\title{
La concepción social del poder en la construcción de la hegemonía: los casos de Gran Bretaña y Estados Unidos
}

DOI: $10.32870 /$ mycp.v2i4.403

José Jesús Bravo Vergara ${ }^{1}$

\section{Resumen}

La hegemonía es un concepto que tiene que ver con la primacía en la posesión de capacidades materiales, pero también en la habilidad para establecer un orden internacional favorable. En la era westfaliana sólo dos Estados han sido considerados como hegemones: Gran Bretaña y Estados Unidos. El primero se planteó como una hegemonía centrada en sus capacidades materiales alentadas por el dominio de las rutas comerciales, un poderío naval indiscutible, el progreso de su revolución industrial, la destreza para mantener el equilibrio entre las grandes potencias de la época y el interés de ejercer un papel relevante en el futuro de la humanidad; mientras que el segundo desarrolló un orden hegemónico basado no sólo en sus capacidades materiales, sino en la aquiescencia del resto de la comunidad internacional motivada por la práctica del multilateralismo, ambos con el entendimiento de la relevancia de la aplicación de una visión social del poder.

Palabras clave: hegemonía, equilibrio de poder, concepción social del poder, multilateralismo y orden internacional.

Artículo recibido el 1 de octubre de 2012 y dictaminado el 16 de abril de 2013.

1. Profesor-investigador del Departamento de Estudios del Pacífico, del Centro Universitario de Ciencias Sociales y Humanidades de la Universidad de Guadalajara. Correo electrónico: braverjoje@ hotmail.com 


\section{Abstract}

Hegemony is a concept related to the primacy on ownership of material capabilities, but also the ability to establish a liable international order. In the so called "Westphalian age" only two states have been considered hegemonic: the United Kingdom and the United States of America. The first one, was conceived as hegemony centered in its material capabilities encouraged by dominance of trade routes, an undisputed naval power, the progress of its industrial revolution, the skills to keep balance between great imperial powers during nineteenth century; the second one developed an hegemonic order based not only in the material capabilities, but also in the acquiescence of international community driven by the multilateralism practice, both states with an understanding of relevance in the application of a social vision of power.

Keywords: hegemony, balance of power, multilateralism, international order, international relations.

\section{Introducción}

La hegemonía tiene que ver con la primacía que señala el hecho de ser el primero dentro de un grupo o sistema. Esto indica que está por encima de los demás e implica la existencia de relaciones de poder entre varios actores. Se trata entonces del desarrollo de capacidades y habilidades que permiten a un actor establecer un orden lo suficientemente ventajoso como para obtener resultados favorables.

En la historia moderna, sólo Gran Bretaña entre 1763 y 1918, y Estados Unidos a partir de 1945 han alcanzado una posición hegemónica debido a sus capacidades materiales, tanto en el ámbito de lo militar, así como en el de lo económico-comercial. En este artículo el autor plantea que dichas capacidades no fueron los únicos argumentos por los que ambas naciones pudieron alcanzar una posición hegemónica; tanto Gran Bretaña como Estados Unidos desarrollaron una dinámica enfocada en la aplicación de una visión social de su poder que les permitió a cada uno estructurar y fortalecer un orden internacional favorable, siendo la implementación del multilateralismo por parte de Estados Unidos la característica que diferencia a ambas hegemonías.

Este trabajo está organizado en cinco apartados. El primero se refiere al concepto de hegemonía y sus orígenes; en el segundo se describe el concepto de hegemonía conforme a las diferentes escuelas de relaciones internacio- 
nales; el tercero se centra en Gran Bretaña como potencia naval, comercial y económica; mientras que el cuarto se enfoca en el desarrollo de la hegemonía estadounidense a través de la visión social de su poder y el multilateralismo como su característica más relevante. Finalmente, un quinto apartado se refiere a las conclusiones del artículo.

\section{Hegemonía: concepto y sus orígenes}

Los griegos fueron los primeros en utilizar la terminología sobre el concepto de hegemonía, el cual se deriva de los antiguos vocablos eghestai, egemone y ehgemonía. El vocablo eghestai significaba la acción de preceder, conducir, guiar, dirigir o estar al frente. La palabra egemone significaba conductor, pero se incluía en el entendimiento de conducir, una connotación militar; se trataba entonces del "guía" y el comandante del ejército. Mientras que la palabra ehgemonía era descrita como la dirección suprema del ejército, el mando absoluto sobre todas las fuerzas militares (Gruppi, 2007). Esto indica que, al menos en un principio, se trataba de un término estrictamente militar.

Durante la época de la guerra del Peloponeso, para ser exacto en la segunda conflagración (431-402 a. C.), Tucídides mencionó a la "ciudad hegemónica" para señalar a Atenas, la ciudad-Estado que mantenía bajo su estricta dependencia a la Liga Marítima Délico-atica y cuya intención no sólo fue la de conservar su poder, sino la de expandirlo a costa de la Liga del Peloponeso “acaudillada" por Esparta (Bengston, 1972: 139-217).

Sin embargo, se le atribuye a Antonio Gramsci (1975) en los llamados Cuadernos de la cárcel, más de 2,000 años después, la connotación política del concepto de hegemonía, así como el empeño puesto en lo que se conoció en el marxismo clásico como la superestructura, un elemento del ámbito cultural por medio del cual se podían realizar acciones políticas y reproducir la hegemonía del proletariado. Gramsci argumentaba que la hegemonía abarca tres estructuras de dominio: la económica, la política y la social. Asimismo, señalaba que esta última estructura es fundamental en el funcionamiento de la hegemonía.

El planteamiento de Gramsci está enfocado en el ámbito doméstico, en donde explicaba que el poder de la burguesía se centraba en la infiltración de los valores burgueses en todos los órganos de la sociedad. En ese sentido, señalaba que la hegemonía es un liderazgo por consentimiento, pero que ello no excluía la noción relativa a la dominación, es decir, a la coerción (Gramsci, 
1975: 18 y 50). En ese sentido, la hegemonía presupone que se deben tener en cuenta los intereses y tendencias de los grupos sobre los cuales se va a ejercer el poder. Supone también la existencia de un equilibrio, así como de compromisos de tipo económico-corporativo que el grupo dirigente debe establecer. Asimismo, aunque la hegemonía se centra en una base ético-política, también debe ser económica y basarse inevitablemente en la función ejercida por el grupo dirigente en el núcleo decisivo de la actividad económica (ídem).

\section{El concepto de hegemonía y las diferentes escuelas de las relaciones internacionales}

En la disciplina de las relaciones internacionales el término hegemonía ha sido el centro de numerosos debates entre las diferentes escuelas. Por un lado, los realistas se basan en el concepto de interés definido en términos de poder para establecer un vínculo entre la razón que trata de comprender y los hechos que deben ser comprendidos (Morgenthau, 1985: 45). Bajo ese esquema y sin dejar de reconocer la existencia de la "anarquía" en el sistema internacional, los Estados buscan poseer las mayores capacidades materiales posibles o incluso la hegemonía porque es algo que consideran muy importante para la obtención del dominio político y económico; ello a su vez es indispensable en el "juego" de la supervivencia. De esta forma, la hegemonía se puede definir como la primacía resultante de la concentración de las capacidades materiales por parte de un Estado - esencialmente en el campo de lo militar-y la voluntad para proyectar dicho poder por medio de la coerción.

En esta escuela la idea desarrollada por John Mearsheimer (2001) y su realismo ofensivo se enfoca en que la mayor preocupación de los Estados es su seguridad en el rubro de lo militar, de modo que entre mayor poder militar tenga un Estado, no sólo aumentará sus oportunidades de supervivencia sino también logrará dominar a otras potencias e implantar un orden favorable. Sin embargo, Mearsheimer señala que existen límites de poder para todas las potencias y que por ello la hegemonía global es improbable; del mismo modo, en todo caso existen hegemonías regionales que desempeñan un rol de balance en otras regiones para mantener el statu quo a su favor.

Dentro de la corriente neoliberal institucionalista, Robert Keohane (1984) señala que un país es hegemónico porque tiene preponderancia en recursos materiales debido a que tiene acceso a las materias primas vitales, al control de las fuentes principales de capital, al mantenimiento de un amplio mercado 
para las exportaciones y a la posesión de ventajas comparativas en bienes con un elevado valor agregado, además de ser más fuerte que cualquier otro país y ostentar capacidad para poder establecer un orden dentro de la política mundial. Bajo esa idea, Keohane menciona que un orden dentro de la política mundial sólo puede ser generado por un único poder predominante que crea regímenes y hace prevalecer reglas fundamentales en el ámbito comercial que gobiernan las relaciones entre los Estados. Asimismo, sostiene que la conservación de dicho orden necesita de la continuidad de la hegemonía. Por esta razón, mientras un hegemón ejerza un mayor dominio en la política económica mundial, habrá un mayor índice de cooperación en las relaciones entre Estados (Keohane, 1984: 31-34). Esta posición es respaldada por el realista Robert Gilpin (1987), quien sostiene que la hegemonía se basa en la creencia general de su legitimidad, es decir, en el consenso por parte de otras grandes potencias que aceptan su liderazgo.

Lo anterior se refleja entonces en la influencia y en los resultados que esta situación produce. Debido a que los neoliberales centran el entendimiento de su seguridad en el campo de lo económico, para el hegemón es esencial mantener su primacía económica sobre otras potencias; por medio de ello puede lograr no sólo la coerción, sino también la cooperación por parte de otros países a través del convencimiento, es decir, del uso del soft power ("poder blando") (Nye, 2003: 30).

En los últimos años se ha desarrollado una visión sociológica sobre el concepto de hegemonía gracias a la escuela constructivista de las relaciones internacionales. En este enfoque, Christian Reus-Smit (2004) señala que un Estado es hegemónico cuando tiene la capacidad de definir las reglas de la sociedad internacional, cuando es lo suficientemente poderoso para mantener las reglas esenciales del gobierno en las relaciones interestatales y cuando tiene la voluntad para hacerlo. En ese sentido, identifica a la hegemonía de un actor sobre la base de un modelo funcional y no sólo con la consideración de lo material.

Reus-Smit (2004) también complementa su concepto sobre hegemonía con el entendimiento de la aceptación del hegemón por parte del resto de los países. Ahí, se respalda en el señalamiento realizado por Robert Gilpin acerca de la creencia general de la legitimidad. Su aportación es que para poder obtener el reconocimiento sobre la legitimidad de su posición hegemónica por parte del resto de los países, el hegemón debe actuar conforme a lo que él denomina la concepción social de poder: es esa sintonía; menciona que 
cuando se habla de un actor como poderoso no se limita al uso de armas o al dinero, sino al éxito para realizar sus metas. Esto indica entonces los siguientes planteamientos: el poder es un módico control sobre los resultados; el poder sólo puede desarrollarse a través del intercambio entre los actores envueltos, es decir, es inherentemente relacional y el poder está irremediablemente enlazado con la negociación.

Bajo este argumento el autor señala que el poder puede ser de tipo moral, esto implica la existencia de consenso acerca de normas y prácticas que un actor promueve y dirige, en este caso el hegemón. El autor también sostiene que la práctica de este tipo de poder es más racional debido a que el hegemón socializa dicho poder a través de la participación en instituciones multilaterales, las cuales a su vez proveen normas, legitiman las reglas institucionales y regulan las relaciones interestatales (Reus-Smit, 2004: 59-62).

Con el argumento que desarrolla sobre la concepción social del poder, Reus-Smit (2004) guía a una visión diferente de la hegemonía, la cual es interpretada como un estatus sancionado socialmente que enfatiza en la legitimidad y el consenso porque los Estados encuentran intereses compatibles con el hegemón. Esta concepción está basada en tres ideas cruciales: a) el hegemón debe adquirir un sustancial recurso de poder material, ello indica que la hegemonía es una forma de jerarquía social basada en el estatus de reconocimiento; b) la hegemonía es un tipo de orden social en el cual su procedencia es reconocida generalmente y las normas sustantivas generan jerarquía social y disminuyen la necesidad de coerción y explotación, y c) la hegemonía es encontrada en la negociación de identidades e intereses.

John Ikenberry y Charles Kupchan (1990) refuerzan este planteamiento. Ellos tampoco niegan la relevancia de las capacidades materiales, pero sostienen que la socialización del poder es sumamente relevante para que un hegemón obtenga el consentimiento de los demás Estados en el desarrollo del orden que él promueve. Por medio de esta dinámica, se interiorizan normas y valores, al mismo tiempo que se debilita el ejercicio coercitivo del poder. Bajo esta explicación, tanto el planteamiento de Reus-Smit como las aportaciones realizadas por Kupchan e Ikemberry no sólo abarcan plenamente las tres estructuras de dominio destacadas por Gramsci, sino que van más allá al explicar finamente el entendimiento sobre la proyección del poder en un orden hegemónico bajo el uso de la concepción social del poder.

Tomando en cuenta lo anterior, una potencia hegemónica es aquella cuyo potencial económico y militar es superior al de cualquier otra, que tiene la 
voluntad y la eficacia de comandar y mantener las reglas esenciales en el sistema internacional y que es capaz de obtener el consenso para llevar a cabo sus metas sin dejar de considerar los intereses de otras potencias, manteniéndose con ello en la cima de la estructura jerárquica del sistema internacional.

\section{Gran Bretaña: una hegemonía comercial y marítima}

Gran Bretaña se convirtió en la primera hegemonía de la era westfaliana gracias a la combinación de tres factores esenciales: su poder militarnaval, la revolución industrial, así como la promoción de una dinámica de comercio internacional que permitió la promoción del comercio internacional y el establecimiento de un sistema mundial en el que trató de reproducir su orden doméstico. El primer factor pudo concretarse gracias a sus victorias militares contra su principal competidor, Francia, en la Guerra de los Siete Años (1756-1763) y en Waterloo en 1815 (Wallerstein, 1989: 77-104). El segundo factor permitió a los británicos consolidar su posición hegemónica porque pudo tener eficiencia en su producción, acceso a las materias primas y a los mercados de bienes finales, así como capacidades materiales y estratégicas suficientes como para monopolizar las rutas marítimas y demandar la apertura de mercados en otros países y colonias. Asimismo, el tercero de los factores pudo ser promovido a través del crecimiento de una economía mundial integrada que logró atraer a más regiones a un comercio transoceánico y transcontinental y a una red financiera centrados principalmente en Gran Bretaña como eje (Kennedy, 2007: 237). A esta etapa, que va desde finales del siglo XVIII hasta principios del XX se le conoce como la Pax Britannica. 
Aún antes de la muerte de Luis XIV en 1715, Gran Bretaña había respondido al expansionismo francés a través de la guerra, y con el respaldo de Holanda, Prusia y Portugal había logrado detenerlo por medio de los tratados que se firmaron en Utrecht en 1713 (Winks, 2000: 315); con dichos tratados se dio fin a la guerra de sucesión española. A partir de entonces comenzó una carrera entre Gran Bretaña y Francia por lograr la hegemonía, una lucha que no terminaría sino hasta un siglo después.

La necesidad de expansión motivó a las dos grandes potencias europeas a entablar una competencia abierta por conquistas territoriales en Asia y América del Norte hasta que estalló lo que se denominó como la Guerra de los Siete Años entre 1756 y 1763, en la cual los británicos derrotaron en una primera etapa de disputas a los franceses. El resultado fue una clara victoria de Gran Bretaña sobre Francia en el dominio de la India en Asia y de Canadá en el norte de América, así como el quiebre del complejo industrial-comercial francés en las costas del Atlántico.

Durante este lapso, la tasa de crecimiento demográfico y la depresión agrícola trajo a finales del siglo XVIII un nuevo problema interno para Gran Bretaña. Su respuesta a esta situación fue que en su esfuerzo por incrementar la producción se motivó la innovación tecnológica, esta situación permitió la invención de la máquina de vapor, y ello a su vez derivó en la Revolución Industrial que llevó a los británicos a distanciarse de Francia en los campos de lo económico, lo tecnológico y lo militar. Por si fuera poco, en Francia se presentó una reacción aristocrática centrada en la imposición de los derechos y privilegios señoriales y en la apropiación de los campos comunales por parte de los mismos señores y de los terratenientes locales. Todo ello en detrimento del grueso de la población (Wallerstein, 1989: 77-104).

En términos generales, Francia se había preocupado demasiado por imponer su voluntad en la Europa continental, ahí centraba también su poder económico aunque poco competitivo. Por su parte, Gran Bretaña había ganado la competencia comercial en ultramar. En ese sentido, el comercio de sus colonias y el de las colonias españolas y portuguesas en América le pertenecía. Sin embargo, tras la Guerra de los Siete Años, Francia intentó debilitar a Gran Bretaña a través del apoyo proporcionado a las 13 colonias británicas de América del Norte que buscaban su independencia de su acérrimo enemigo, pero su esfuerzo fue infructuoso debido a que una vez independizadas, dichas ex colonias continuaron un comercio intenso con su antigua metrópoli. A su 
vez, Francia incrementó su deuda con los bancos europeos como resultado del apoyo que otorgó a las fuerzas independentistas americanas.

La Revolución Francesa y el ascenso al poder de Napoleón Bonaparte configuraron un escenario en donde Francia intentó de nueva cuenta competir por la hegemonía en Europa continental. Entre 1804 y 1811, durante la fase expansiva del imperio napoleónico, Francia pudo ocupar Holanda, Bélgica, España, Portugal y parte de Italia. Asimismo, tuvo cierto dominio sobre los monarcas de Austria y Prusia, al tiempo que mantuvo cierta influencia sobre Rusia e impuso un bloqueo a los británicos. Sin embargo, su invasión a Rusia en 1812 resultó en una catástrofe y los británicos, respaldados por rusos, austriacos y prusianos aprovecharon este problema para anular definitivamente el poder francés en el continente en la célebre batalla de Waterloo.

Con Napoleón vencido y Francia sometida, Gran Bretaña, Rusia, Prusia y Austria se reunieron en Viena y acordaron cuáles serían los principios que regirían a partir de entonces las relaciones internacionales. El más importante de estos principios fue el de equilibrio de poder entre las potencias. El entendimiento de que el equilibrio garantizaba la paz era la teoría del entonces ministro austriaco, Clement Von Metternich, ${ }^{2}$ quien argumentaba que era preciso que ningún país fuera más poderoso que el resto de las potencias (Alija Garabito, 2001: 70). Por su parte, Karl Polanyi (1989) señala que el equilibrio de poder impidió que hubiera guerras largas y agotadoras entre las grandes potencias de la época, al tiempo que se constituyó en una institución nacional inglesa de carácter explícitamente pragmática, debido a que se convirtió en su única opción viable de seguridad frente a las potencias dominantes del continente. ${ }^{3}$

Bajo este contexto, Gran Bretaña enfocó su atención en el hecho de que el imperio debía de servir a sus intereses fundamentales, por ello se empeñó en conservar el dominio de las rutas comerciales marítimas en América y Asia, tal y como lo demostró con su acercamiento a Estados Unidos cuando

2. En los asuntos internacionales el equilibrio de poderes era casi un principio cósmico, sin éste no podía existir el reposo y el reposo era esencial para la normal felicidad del hombre (véase en Alija Garabito, 2001: 70).

3. A pesar de ser un planteamiento promovido por Metternich, para la Gran Bretaña la política de equilibrio de poder fue la consecuencia de su característica geográfica insular, ya que este sistema le permitía organizar alianzas bajo condiciones especiales favorecedoras en las que el objetivo era impedir que alguna de las grandes potencias de la época acumulara demasiado poder en detrimento del statu quo (véase en Polanyi, 1989: 18 y 366). 
rechazó las declaraciones de la Santa Alianza - Rusia, Prusia y Austria- que amenazaba con restaurar las colonias españolas en el continente americano, una situación que afectaba de forma directa sus intereses comerciales. Bajo esta peligrosa tendencia, el principio de equilibrio de poder se convirtió en uno de los ejes en los que Gran Bretaña cimentó su hegemonía, y si por un lado intervino en asuntos tales como la independencia de Bélgica y Grecia, con el riesgo de transformar el statu quo que las grandes potencias habían impuesto con el Congreso de Viena a partir de 1815, por otro invocó precisamente el principio de equilibrio del poder y dirigió de forma exitosa una coalición contra el expansionismo de Rusia en la Guerra de Crimea (1854-1856). Del mismo modo, los británicos procuraron permanecer alejados de algunos de los grandes conflictos en el continente europeo durante el siglo XIX, siempre y cuando éstos no afectaran directamente sus intereses, por esta razón evitaron verse envueltos en las guerras de Prusia contra Dinamarca en 1864, contra Austria en 1866 y contra Francia en 1870, las cuales permitieron que Alemania se unificara.

Gran Bretaña también aprovechó el contexto inmediato sobre los intereses existentes entre las grandes potencias durante ese periodo, pues mientras que Austria, Rusia, Prusia y Francia optaron por reconstruir sus respectivas economías y sistemas políticos dañados por la Revolución Francesa y las guerras napoleónicas, los británicos, quienes tuvieron pérdidas infinitamente menores a las sufridas por sus aliados, se enfocaron en fortalecer su flota naval y expandirla alrededor del mundo (O’Brien, 2002), así como a afianzar sus colonias, las cuales sumaban alrededor de 31 millones de kilómetros cuadrados y un total cercano a los 500 millones de personas (ídem). De la misma forma, su interés sobre la expansión del comercio permitió a los británicos alcanzar el Tratado de París de 1856, el cual garantizaba los derechos de los barcos mercantes neutrales y de países participantes en tiempos de guerra (ídem). Lo anterior implicó la construcción de un orden político económico estable en el que Gran Bretaña fungía como el actor más relevante en el contexto internacional, con un liderazgo económico mundial, con el respaldo de una fuerza naval superior a la de cualquier otra potencia y con el entendimiento de que tenía el interés, y hasta cierto punto la responsabilidad, hacia la generación de un orden internacional general en el que siempre se viera favorecido.

No obstante lo anterior, John Mearsheimer (2001) sostiene que a pesar de ser considerada como la potencia hegemónica durante el siglo XIX, Gran Bretaña nunca fue lo suficientemente poderosa como para dominar toda Eu- 
ropa. Por ejemplo, en el aspecto militar, Niall Ferguson (2003) aduce que Gran Bretaña estaba limitada a su poder naval, y salvo la Guerra de Crimea en la que unió fuerzas con Francia, el Imperio otomano y el Reino de Piamonte-Cerdeña contra Rusia, evitó confrontar sola y abiertamente a las grandes potencias de la época. Por su parte, Richard Rosecrance (2002) coincide con Niall Ferguson al tiempo que señala que los británicos podrían imponer condiciones navales en el mundo, pero que nunca fueron capaces de imponer plenamente la paz en el continente europeo.

En referencia a lo anterior, si bien es cierto que el enfoque de este trabajo no se centra en la consideración de las capacidades militares como el único elemento que conforma el concepto de hegemonía, en contradicción con las perspectivas de Mearsheimer, Ferguson y Rosecrance citadas en el párrafo anterior, sería una omisión no señalar que la tecnología derivada de la Revolución Industrial desarrollada en Gran Bretaña a finales del siglo XVIII produjo un impacto lento pero sostenido sobre el arte de la guerra terrestre y naval, algo que desde la perspectiva del historiador Paul Kennedy (2007) influyó en el resultado militar de los conflictos que Gran Bretaña tuvo en el transcurso del siglo XIX. ${ }^{4}$

Sin embargo, como ya se señaló anteriormente, en el ámbito militar su función más relevante fue el desempeño que ejerció como país guía y garante del equilibrio de poder en las relaciones internacionales de la época gracias a la aplicación de las siguientes reglas: actuar para incrementar capacidades, pero negociar antes que pelear; pelear antes que dejar pasar una oportunidad para incrementar sus capacidades; parar de pelear antes que eliminar a un actor esencial; actuar para oponerse a cualquier coalición o actor solo que tienda a asumir una posición dominante respecto al resto del sistema; actuar para limitar a los actores que convengan principios de organización supranacional que compitan con sus principios, y permitir que los actores derrotados o limitados puedan entrar de nueva cuenta al sistema como socios (Maurseth, 1964: 127).

Es necesario precisar que además de las capacidades materiales y de procurar mantener el statu quo, el equilibrio de poder no fue la única medida que Gran Bretaña utilizó para conservar su posición hegemónica; Polanyi (1989) señala que durante el siglo XIX la civilización se asentó sobre otros tres

4. La participación británica fue sumamente exitosa en las guerras napoleónicas, la independencia de Grecia, la neutralidad de Bélgica y la Guerra de Crimea. 
principios ordenadores del sistema internacional: el patrón-oro, el mercado autorregulador y un Estado liberal. ${ }^{5}$ En dicho escenario, en el que además se estaba desarrollando una feroz competencia colonialista, Gran Bretaña promovió un orden internacional a partir de que poseía la directriz de una economía mundial integrada, el control sobre las rutas comerciales y las redes financieras, así como un enorme imperio de ultramar que respaldaba su déficit comercial (Silver, 2003).

A través de lo que se denominó el "capitalismo gentil" (Cain y Hopkins, 1987: 8), el imperio británico intentó desarrollar un sistema mundial en el cual se expresara su orden doméstico utilizando al comercio internacional como "herramienta" para producir una gran apertura financiera alrededor del planeta, así como el desarrollo de servicios comerciales y manufactureros dentro y fuera de su propio imperio. La expansión de la libra esterlina como moneda de intercambio en el comercio internacional y el incesante crecimiento de las inversiones británicas en ultramar fueron las principales expresiones de esta tendencia (Hopkins, 1988: 7).

Asimismo, además de su moneda, el uso del inglés como idioma básico para las transacciones comerciales en casi todo el mundo reforzó el poder británico, permitiendo una constante reproducción de su cultura y un mejor entendimiento de sus prácticas, todo ello en favor de sus intereses políticos y económico-comerciales. Y aunque era indudable que la vasta ambición imperial británica de expansión territorial hacia otros continentes estaba enfocada en satisfacer las necesidades económicas y comerciales del imperio, la idea de llevar a cabo la misión de propagar la civilización europea invocaba la vocación británica de asumir un papel "determinante" en el porvenir del mundo (Renouvin y Duroselle, 2000: 220).

Según Joseph (2008), un proyecto hegemónico es más exitoso cuando se basa en un profundo proceso social y un desarrollo posterior mediante el desarrollo de una estrategia estatal. Durante la segunda mitad del siglo XIX, para Gran Bretaña este planteamiento tuvo sentido no sólo en la medida en que como meta de Estado construyó un imperio y expandió la civilización europea, sino también en el logro de socializar prácticas económico-comerciales

5. El patrón-oro representaba el orden de una organización económica mundial; el mercado autorregulador era considerado como el productor de un bienestar material sin precedentes, y el Estado liberal promovió la creación de leyes que permitieron el crecimiento de una economía de mercado (véase en Polanyi, 1989: 18). 
haciendo uso de la manipulación del balance de poder en el "viejo continente" en una forma en que pudo asegurar un ambiente permisivo hacia los países de Europa occidental para adoptar formas de organización liberales sin provocar riesgo de intervención de los antiguos regímenes (Cox, 1987: 148), el cual era otro de los principios del Congreso de Viena. Asimismo, tomando como referencia la concepción social de poder de Reus Smit (2004), hay que considerar que la hegemonía británica pudo sustentarse no sólo gracias a sus capacidades materiales para definir las reglas de la sociedad internacional y a la voluntad para hacerlo por medio de un manejo magistral del equilibrio de poder entre las grandes potencias, sino también debido a la aquiescencia por parte del resto de las naciones en su aceptación como líder en la promoción de las prácticas económicas y comerciales, así como participante y garante en los grandes acuerdos políticos internacionales de la época. ${ }^{6}$ En pocas palabras, a través de dichas acciones Gran Bretaña pudo aplicar una visión social de su poder.

Finalmente, así como la Pax Britannica se pudo suscitar gracias a la convergencia entre la retórica oficial en favor del libre comercio, la diplomacia y el mantenimiento del compromiso con otras potencias en lo que se refiere a las relaciones comerciales a un nivel de igualdad (O'Brien, 2002), dicha Pax Britannica comenzaría a tambalearse con la unificación de Alemania y el ascenso imparable de Estados Unidos, pues el crecimiento económico, tecnológico y militar de ambas naciones a finales del siglo XIX y principios del XX planteó un nuevo escenario mundial en el que los británicos comenzaron a considerar la idea de que ya no eran invencibles y de que no eran los únicos que estaban en la cúspide, por lo que irremediablemente precisaban de las alianzas para sostener su posición o para amortiguar el declive de su hegemonía.

\section{La hegemonía de Estados Unidos: el inicio y la aceptación de su posición hegemónica}

A principios del siglo xx Alemania y Estados Unidos se acercaron a los índices de desarrollo británico, pero no fue sino hasta 1918 con el fin de la Primera

6. Entre 1882 y 1914, Gran Bretaña participó de forma exitosa en el reparto de colonias en África y Asia, en la guerra de los boers (1889-1902) y en la crisis de Fashoda en 1899, aunque es preciso tomar en cuenta que los británicos procuraron no involucrarse en conflictos que no afectaran directamente sus intereses. 
Guerra Mundial que Gran Bretaña perdió definitivamente su posición hegemónica. Ese momento marcó una nueva etapa en el contexto internacional, pues la participación de Estados Unidos en el conflicto mencionado fue determinante en el triunfo de las potencias de la Entente. Asimismo, el objetivo de establecer un nuevo orden internacional solamente podría ser logrado por Estados Unidos debido a que las potencias europeas estaban completamente agotadas y endeudadas con Washington. ${ }^{7}$ Aprovechando el vacío de poder que habían dejado éstas, el entonces presidente estadounidense Woodrow Wilson llevó a cabo la laboriosa tarea de plantear cuáles serían los nuevos principios que regirían el sistema internacional tras el fin de la guerra.

Como fundamentos relevantes de sus 14 puntos, estaban: afianzar la paz de los mares; eliminar barreras arancelarias; la reducción de las fuerzas militares de las diversas potencias; y garantizar el autogobierno a las naciones europeas por medio de la Sociedad de Naciones. En suma, había establecido principios posibles de realizar, de modo que el resto de los Estados triunfadores y aquellos derrotados o recientemente independientes aceptaron (Zorgbibe, 1997, tomo I: 351-371). No obstante, Estados Unidos, el gran acreedor de las grandes potencias y máximo productor mundial desde entonces, no tuvo la voluntad de asumir el papel de hegemón en la Sociedad de Naciones debido a que la mayoría en el Senado no deseaba que su país se comprometiera en los asuntos europeos ni que éstos se entrometieran en los "asuntos americanos”. De esta forma, la posibilidad de un orden estable perdurable fracasó, en especial cuando Alemania, Italia y Japón invadieron o anexaron a terceros países por encima de la Sociedad de Naciones (Du Boff, 2003).

El desarrollo de la Segunda Guerra Mundial involucró de nueva cuenta a Estados Unidos, y con ello se planteó la necesidad de establecer un nuevo orden una vez que las potencias del Eje fueron derrotadas en el transcurso de 1945. A diferencia de 1919, ahora Estados Unidos había asumido el papel de hegemón. Las características de este nuevo hegemón eran diferentes de las que en su momento tuvo Gran Bretaña. Su productividad abarcaba alrededor de $50 \%$ de la producción total global, contaba con $82 \%$ de las inversiones mundiales y el control sobre $59 \%$ de las reservas mundiales de petróleo (ídem). Asimismo, su poder militar era enorme no sólo en cantidad, sino también en calidad, pues incluso tuvo el monopolio del arma nuclear durante cuatro años.

7. Desde 1916 Nueva York había sustituido a Londres como la capital financiera del mundo (véase en Hodgson, 2009: 21). 
En suma, Estados Unidos alcanzó en esa época la mayor capacidad material en relación con el resto del mundo.

La magnitud de su potencial económico y comercial proporcionó nuevas bases en el sistema internacional. El dólar se confirmó como el nuevo patrón de compra-venta mundial y la creación de instituciones internacionales que planteaban una renovada interacción en el comercio y en la petición de créditos para el desarrollo de los países, propuso una supervisión en la que Washington promocionaba regímenes comerciales y reglamentaba la nueva dinámica del sistema internacional. Asimismo, era el único con capacidades materiales y liderazgo político para defender a sus aliados Francia y Gran Bretaña de la nueva amenaza militar e ideológica que representaba la Unión Soviética, al tiempo que se comportaba con magnanimidad en el trato a sus enemigos vencidos, Alemania y Japón, a quienes además incluyó en sus alianzas militares. ${ }^{8}$

Estados Unidos también pudo estructurar un orden estable en el sistema internacional a través de una serie de instituciones internacionales como Naciones Unidas y la Organización de Estados Americanos (Mols, 2010), así como de la promoción de algunos principios que asumía como propios: la democracia, el libre mercado y los derechos humanos. Del mismo modo, a pesar de las dimensiones de su poder, tuvo que renunciar muchas veces a la imposición violenta constante de dichos principios y recurrir al ejercicio de una agenda de negociación multilateral e incluyente, la cual se centró principalmente en Europa occidental, a la que apoyó por medio del Plan Marshall y de la OTAN, los ejes de su política de contención contra la Unión Soviética en la región. ${ }^{9}$

En suma, Estados Unidos pudo tener éxito en la consecución de resultados debido no sólo a que poseía grandes capacidades materiales, sino a que su política provocó que se desarrollaran una serie de prácticas propias en el sistema internacional. Muchas de estas normas tuvieron capacidad adaptativa y reproductiva, incluso se institucionalizaron por medio del establecimiento

8. Estados Unidos organizó una red de alianzas bilaterales y multilaterales en las cuales incluyó a Alemania (occidental) al interior de la oTAN y a Japón en un Tratado de Defensa. Manfred Mols sostiene que hasta 1949 este tipo de alianzas de dimensión global eran desconocidas en la historia mundial (véase en Mols, 2010: 14).

9. "Nuestra seguridad nacional y la seguridad del mundo requerirán importantes servicios armados, particularmente en el servicio extranjero” (Truman, 1946, citado en Legro, 2000). 
de regímenes y organismos internacionales. ${ }^{10}$ La dinámica multilateralista empleada por Washington permitió la producción de reglas constitutivas que ordenaron las relaciones en dominios dados de la vida internacional, al tiempo que promovió un orden de seguridad al que la gran mayoría pudo acceder (Ruggie, 1992: 572). Así, por medio de una intensiva construcción de instituciones internacionales, Estados Unidos pudo desarrollar una estructura de relaciones destinada a reproducir patrones de comportamiento (Cox, 1987: 39), y como ya se señaló anteriormente, durante mucho tiempo se autorrestringió en la posibilidad de romper con el orden que él mismo había creado, una tendencia que descansa en lo que Rapkin y Braaten (2009) han denominado "legitimidad constitutiva".

En una ilustración sobre los compromisos y las capacidades estadounidenses, Paul Kennedy (2007) señala que a inicios de la década de 1970 Estados Unidos tenía más de un millón de soldados en 30 países, era miembro de cuatro alianzas defensivas regionales y partícipe en una quinta. Tenía tratados de defensa mutua con 42 Estados, era miembro de 53 organizaciones internacionales y proporcionaba ayuda militar a casi 100 países. Asimismo, desde el fin de la Segunda Guerra Mundial, Estados Unidos destinó gran parte de sus energías a difundir su cultura y sus valores - poder blando-, los cuales eran respetados e imitados en gran parte del mundo. No obstante, como ya se ha mencionado con anterioridad, una hegemonía no puede ser entendida como un orden construido únicamente por la propiedad de capacidades materiales, ni puede ser entendido como el control de un gran poder sobre el resto de los actores en un contexto determinado, sino como un tipo especial de dominio que envuelve algunas concesiones e intereses de otros poderes, en el que los valores y entendimientos acerca de la naturaleza de dicha estructura permea un sistema entero (Cox, 1987: 42) y crea por medio de patrones generalizados de conducta, un beneficio común y una toma de decisiones multilateral (Ruggie, 1992: 567), produciendo a su vez lo que puede ser definido como una "reserva" de legitimidad (Rapkin y Braaten, 2009: 121-123 y 132).

A través de la promoción de normas internacionales de interés común Estados Unidos guió a la aceptación de reglas multilaterales, instituciones, comunidad democrática, mercados abiertos, así como a una nueva visión de

10. "La estrella que nos guía es el principio de cooperación internacional. Con ese concepto hemos hecho un compromiso tan profundo como el que más en la historia" (Truman 1949, citado en Legro, 2000). 
una sociedad progresiva internacional (Ikenberry, 2005), lo que permitió a su vez acceder a cierta estabilidad internacional. En pocas palabras, Estados Unidos hizo uso de la concepción social de su poder, porque tuvo la voluntad de establecer una relación de negociación con sus aliados a través de una política incluyente en la toma de decisiones sobre temas como la seguridad internacional y el desarrollo económico (Reus Smit, 2004: 56 y 57); esta política produjo consenso y, por ende, obtuvo legitimidad para la nueva estructura social promovida y dirigida por Washington. Como argumento adicional, y sin dejar de lado la confrontación ante el reto comunista, tuvo que incluir en dicha estructura a la Unión Soviética como una estrategia destinada a contener a un Estado política y militarmente poderoso, además de decidido y temerario. ${ }^{11}$

Durante la década de 1970 Estados Unidos sufrió una serie de problemas económicos, políticos y militares debido a un cúmulo de eventos desafortunados, como su intervención en Vietnam, la crisis del petróleo de 1973, el escándalo del Watergate en 1974 y el expansionismo militar soviético en Afganistán en 1979 (Kennedy, 2007: 641). Sin embargo, la posición hegemónica estadounidense persistió gracias a sus capacidades materiales, a la continuidad en la percepción de la amenaza soviética al mundo occidental, a la permanencia de la mayoría de los regímenes económicos, a las instituciones internacionales que había creado y promovido en el transcurso de la Guerra Fría, pero especialmente a la continuidad en el ejercicio de la concepción social del poder, por medio del cual mantenía la aquiescencia de sus tradicionales aliados, así como de gran parte de la sociedad internacional.

De esta forma, aunque la competencia militar y estratégica con la Unión Soviética le dejó vivencias amargas, especialmente durante la década de 1970, la llegada al poder de Ronald Reagan en 1981 ayudó a replantear la política estadounidense en el fortalecimiento del entendimiento político con sus aliados y en el despliegue de su estrategia hacia su rival por medio de una dinámica agresiva centrada en una constante carrera armamentista. Esta situación perjudicó severamente a la URSS, que se vio profundamente afectada por los problemas económicos, políticos y étnicos que tenía en su interior, y todo en su conjunto la hizo derrumbarse hasta el punto de su desintegración. Estos

11. La contención fue la denominación de la política estadounidense hacia la URSs. Marcaba el fin de la cooperación con ésta y el inicio de la construcción de un "muro" que planteaba una oposición al avance soviético, principalmente en Europa occidental; no obstante, mantenía su inclusión en los grandes temas mundiales en el marco del Consejo de Seguridad de Naciones Unidas (véase en Gaddis 2002: 63). 
hechos proporcionaron prestigio a Estados Unidos, debido a que resultó ser la potencia triunfadora en el conflicto con los soviéticos. Al mismo tiempo, permitió la confirmación de una posición hegemónica que había adquirido desde 1945.

Tras el fin de la Guerra Fría la situación comenzó a cambiar en el entorno internacional; la competencia soviética había desaparecido y había triunfado la propuesta que representaba Estados Unidos. El entonces presidente estadounidense George Bush padre lanzó la consigna de un "nuevo orden mundial con paz duradera bajo su liderazgo", el cual descansaría en la democracia y la economía de mercado (Kagan, 2008: 6). En una primera instancia, Bush padre optó por mantener la continuidad con el pasado reciente y utilizó su victoria en la Guerra Fría de forma pragmática pero prudente. Lideró una coalición contra Irak en enero de 1991 para desocupar Kuwait y apoyó la unificación de Alemania, pero procuró no inmiscuirse en la desintegración soviética. No obstante, durante su administración, Bush padre prefirió no desmantelar su enorme aparato militar; lejos de ello, por medio de la Defense Planning Guidance invitó a otras potencias a evitar balancear su poder o revocar el orden económico y político establecido. ${ }^{12}$

Posteriormente, durante la administración de Bill Clinton (1993-2000), se dio la confirmación del orden económico-comercial mundial a través de la creación de la Organización Mundial del Comercio en 1995. Asimismo, aunque en esta administración también se inició lo que se conoce como la "revolución en asuntos militares" (Joxe, 2002: 146), existía el compromiso de la administración Clinton de actuar multilateralmente (Soderberg, 2005: 152), y ello se expresó en varios temas, como su intervención y posterior promoción de paz en las guerras yugoslavas con las Pláticas de Dayton en 1995, la intervención junto a la OTAN en Kosovo en 1999 y las Pláticas de las Cuatro Partes junto a Corea del Norte, Corea del Sur y la República Popular de China en 1996 (Kagan, 2008: 99). En el campo económico, Estados Unidos comenzó a sufrir el inicio de una competencia con la Unión Europea, Japón, China y los países de América del Sur, al mismo tiempo que estableció un tratado de libre comercio con Canadá y México. Henry Nau (2002) señala que bajo estas circunstancias

12. "Estados Unidos debe mostrar liderazgo necesario para establecer y proteger un nuevo orden que abrace la promesa de convencer a potenciales competidores de que ellos no necesitan aspirar a engrandecer su rol o perseguir de forma agresiva sus legítimos intereses" (véase en Defense Planning Guidance, 1992). 
se estaba creando un nuevo equilibrio económico. Sin embargo, la dinámica multilateral que el gobierno estadounidense continuaba desarrollando en las problemáticas mundiales y la innegable voluntad de permanecer en la conducción y el cuidado del orden mundial de una forma incluyente, hacía que el resto de las potencias continuaran otorgándole su respaldo, por lo que seguía siendo considerado como el hegemón.

Sin embargo, con el ascenso de George W. Bush y de los conservadores en sus administraciones de 2001-2005 y de 2005-2009, Estados Unidos comenzó a desarrollar su política exterior centrado únicamente en sus propios intereses, de esta forma abandonó o rechazó tratados de interés mundial como el Tratado de Reducción de Armas Estratégicas (START), el Protocolo de Kyoto y la Corte Penal Internacional. Asimismo, en el seno del Consejo de Seguridad de Naciones Unidas propuso la iniciativa de atacar Irak bajo la acusación de detentar armas de destrucción masiva (DMW) y de tener vínculos con la red terrorista $\mathrm{Al}$ Qaeda sin tener prueba de ello en ninguno de los casos, propuesta que el grueso de los miembros del Consejo de Seguridad rechazó.

Esta situación resultó en la mayor derrota diplomática para la Casa Blanca en los últimos años; no obstante, el Pentágono lanzó su ataque contra el país árabe. Dicha decisión política le trajo un mayor desprestigio a Estados Unidos, no sólo por ignorar la posición del máximo órgano de seguridad mundial, sino también porque una vez ocupado Irak, el mundo entero se dio cuenta de las torturas y las humillaciones con las que los soldados estadounidenses trataban a sus prisioneros de guerra iraquíes. Estos hechos quedarían evidenciados cuando la administración de Bush Jr. tuvo que aceptar que nunca encontraron armas de destrucción masiva ni vínculos del régimen de Saddam Hussein con Al Qaeda, tal y como lo publicaría años más tarde el propio Bush Jr. en sus memorias (Bush, 2010: 268 y 269).

Bajo este escenario, Estados Unidos comenzó a perder la influencia de que en otros tiempos gozaba. La emisión de una imagen agresiva y revisionista derivó en la falta de apoyo de muchos de sus principales aliados al interior de los organismos internacionales; tales fueron los casos de la negativa de la Junta Interamericana de Defensa (JID) a la propuesta estadounidense de convertir dicha junta en un organismo de cooperación contra el terrorismo y el rechazo a la proposición de "monitorear la democracia" lanzada en junio de 2005 durante la xxxv Asamblea de la Organización de Estados Americanos (OEA) celebrada en Florida, en donde con excepción de Colombia y El Salvador, los miembros de la OEA se rehusaron a aceptar la propuesta presentada 
por la entonces secretaria de Estado, Condoleeza Rice, quien demandaba la creación de una instancia conformada por los gobiernos de algunos países para monitorear decretos, leyes y medidas aprobadas por las legislaturas de los Estados pertenecientes a la OEA pero que "representaran una amenaza" para la democracia (Petras, 2005).

Por su parte, en Eurasia, por conducto de la Organización para la Cooperación de Shangai, Rusia y China han comenzado a desarrollar una política de contención destinada a impedir que Estados Unidos despliegue tropas en Asia Central. Asimismo, la intervención militar rusa contra Georgia, el aliado regional más importante de Estados Unidos entre las ex repúblicas soviéticas en agosto de 2008, la obtención del misil con cabeza nuclear por parte de Corea del Norte - país en el que tiene una mayor influencia China-y la continuación del programa nuclear de Irán, sin que Washington haya podido hacer nada, muestra que algunos de sus antiguos rivales han comenzado a desplegar una dinámica destinada a tratar de balancear el poder militar estadounidense o al menos disminuir la influencia de la Casa Blanca. Lo anterior evidencia que al menos en esa zona se ha desarrollado un rechazo manifiesto a ciertos abusos del orden impuesto por Estados Unidos.

La llegada a la presidencia de Estados Unidos del demócrata Barack Obama en enero de 2009 planteó una perspectiva favorable en el ambiente internacional, pues a pesar de que asumió el poder en medio de la peor crisis económica y financiera de su país desde 1929, su perspectiva sobre las necesidades de Estados Unidos en materia de política exterior se enfocó en tratar de recuperar la influencia perdida durante la administración anterior. En una primera instancia, Obama resaltó la relevancia de la corresponsabilidad en temas de seguridad y, por ende, en la práctica multilateralista bajo el argumento de que el poder estadounidense sólo puede crecer cuando es utilizado con prudencia y de que la seguridad del orden mundial es algo que compete a todos (The New York Times, 2009). Bajo este planteamiento, enfocó su atención en asegurar su posición en Afganistán, ofreció el cierre de la cárcel en Guantánamo, convocó a un acercamiento con Irán e hizo el esfuerzo por restaurar sus relaciones con Rusia. Del mismo modo, procuró no inmiscuirse de forma unilateral en los levantamientos populares que derrocaron los regímenes de Hosni Mubarak en Egipto, de Muammar Gadafi en Libia, al tiempo que aún no ha intervenido de forma unilateral en la guerra civil en Siria que pretende derrocar al presidente Bashar Al-Saddat. 
Sin embargo, si bien es cierto que el ascenso de Obama despertó cierta esperanza de que Estados Unidos actuaría de forma multilateral en el contexto mundial, tal y como se mostró con el otorgamiento del Premio Nobel de la Paz en 2009 sin tener una razón de peso para ello, también es cierto que el recrudecimiento de la violencia en Afganistán, la reapertura de la cárcel de Guantánamo, los escándalos de WikiLeaks —donde quedaron evidenciadas las actividades de espionaje contra diversos gobernantes del mundo desplegadas por el gobierno estadounidense-, y el fracaso de la Cumbre sobre el Cambio Climático en Copenhague, han seguido afectando de forma negativa la imagen de Estados Unidos como un hegemón benévolo; lo anterior no significa que su posición hegemónica esté próxima a derrumbarse, pero sí que ésta se ha visto directamente disminuida en cuanto a su imagen por sus responsabilidades no asumidas, al negarse a participar en algunos de los acuerdos más relevantes para la sociedad mundial, tales como la Corte Penal Internacional y lo relativo a los acuerdos sobre el cambio climático. Asimismo, la inercia de las acciones de la anterior administración hace que cada decisión actual que tome Washington en casi cualquier asunto de interés mundial, debe ser hecha con mucha mesura para que ello no sea interpretado como una amenaza y ponga a la defensiva al resto de las grandes potencias, una situación que afectaría de forma severa el orden favorable que la Casa Blanca desea.

\section{Conclusión}

La hegemonía es un concepto que se refiere a la relación de poder en la que un actor que posee la mayor capacidad material, prestigio basado en credibilidad, así como la voluntad para ejercer liderazgo y el consenso de los demás, es capaz de coordinar y dirigir un orden social jerárquico con base en un patrón general de principios negociados que permiten la construcción de una estructura de interacción regulada por normas e instituciones internacionales.

Asimismo, los hegemones son actores que gozan del dominio de las estructuras de poder como la política, la económica y la social. En ese sentido, poseen capacidades materiales superiores a las de cualquier otro actor, y suficiente poder contextual como para construir una estructura de poder destinada a establecer un orden internacional favorable a sus intereses. De esta forma, aunque con diferentes características y dimensiones de poder, Gran Bretaña y Estados Unidos han podido ostentar una posición hegemónica en los tiempos modernos. 
Ambos países han podido figurar como los hegemones debido a que pudieron configurar un orden internacional en donde sus reglas han regido las diferentes dimensiones de las relaciones internacionales. En una primera instancia, Gran Bretaña por medio de sus capacidades materiales centradas en su poder económico, tecnológico y militar-naval pudo establecerse como garante del equilibrio político y militar en el mundo, y si bien es cierto que no se confrontó sola y de forma abierta con alguna gran potencia durante el siglo XIX, sí lo es el hecho de que consiguió promover y dirigir coaliciones que impidieron que la Francia napoleónica en 1815 y el expansionismo de la potencia rusa durante la Guerra de Crimea (1854-1856) pudieran romper un orden internacional dominado por su comercio y su dominio naval.

Sin embargo, fue la aplicación de la concepción social de su poder, la visión estratégica a través de la cual pudo respaldar con mayor fuerza su posición hegemónica. A través de una interesante interacción entre el comercio internacional y el uso del inglés como un medio de comunicación que permitió la expansión de sus intereses económicos y su cultura, pudo traducir su orden doméstico en un dinámico sistema económico mundial que produjo no sólo una gran apertura financiera, el desarrollo de servicios comerciales y manufactureros alrededor del mundo, la promoción de la adopción de formas de organización liberales en los países de Europa occidental, la aceptación por parte de éstos acerca de dicha dinámica, así como la reproducción de su cultura que estaba respaldada en la asunción de una misión dirigida a propagar la civilización europea y a la vocación explícitamente británica de ejercer un papel determinante en el futuro de la humanidad, tal y como lo hizo, entre otras cosas, con la promoción de la abolición de la esclavitud a mediados del siglo XIX.

En el caso de Estados Unidos, su posición hegemónica ha estado respaldada no sólo en el potencial de sus capacidades materiales, sino en un prestigio basado en la credibilidad, así como en la voluntad para ejercer liderazgo y el consenso de los demás. A través de las grandes instituciones internacionales, Estados Unidos pudo hacer desde 1945 que los patrones internos de comportamiento se reprodujeran constantemente en el sistema internacional. Asimismo, aceptó negociar e incluir en el orden hegemónico que promovía, los intereses de otras grandes potencias, incluso consideró las preocupaciones de su enemiga, la Unión Soviética.

Posteriormente, salió avante al final de la Guerra Fría y con ello reforzó su posición como hegemón. Después, en una continuidad de la aplicación de 
la concepción social del poder, siguió promoviendo la democracia, y su liderazgo resultó crucial en la pacificación de los Balcanes en 1995 y en 1999. En pocas palabras, hasta 2000 Estados Unidos gozaba de una gran credibilidad en el contexto internacional. Asimismo, su posicionamiento en la cima de la sociedad internacional era incuestionable, así como su preocupación por un orden que le siguiera favoreciendo en sus intereses y que a la vez fuera incluyente con los intereses de otros.

Sin embargo, a partir del ascenso al poder de George W. Bush en 2001, y en especial con la invasión a Irak en 2003, Estados Unidos comenzó a sufrir un constante desprestigio por causa de sus acciones unilaterales, las cuales comenzaron a ser vistas como el debilitamiento del orden internacional que él mismo había promovido anteriormente y que los demás habían aceptado. De esta forma, si bien es cierto que Estados Unidos todavía ostenta mayores capacidades militares que cualquier otra potencia y aún posee la economía nacional más grande del planeta, también es cierto que debido a las características de su hegemonía sustentada en el consenso y, por ende, en la legitimidad otorgada gracias a la socialización de su poder, el resto de los países, incluyendo la mayoría de sus aliados, durante las administraciones de George W. Bush comenzaron a alejarse, e incluso a forjar un nuevo tipo de equilibrio de poder sustentado en los acuerdos establecidos en las instituciones internacionales, así como en el desarrollo de un balance "suave" frente a las acciones unilaterales, una situación que hasta el momento, a pesar de los esfuerzos de la administración de Barack Obama a partir de 2009 no ha cambiado mucho para Washington.

Finalmente, se puede decir que tanto Gran Bretaña como Estados Unidos pudieron ascender a una posición hegemónica debido a su primacía en las capacidades materiales (económicas y militares), a la voluntad de asumir dicha posición, así como al consenso de gran parte de la sociedad internacional, y si bien es cierto que existieron algunas características que diferenciaron el orden hegemónico que desarrollaron en sus respectivas épocas, también lo es el hecho de que coincidieron en la aplicación de la concepción social de su poder. Asimismo, en el caso británico, una vez que su posición hegemónica se vio quebrantada, Londres decidió pasarse al lado del nuevo hegemón y atenuar con ello su declive.

Por su parte, como ya se señaló anteriormente, Estados Unidos fortaleció su posición hegemónica por medio del ejercicio de la concepción social de su poder, en la que ha incluido al resto de las grandes potencias en el desarrollo 
de un orden mundial respaldado primordialmente por el ejercicio del multilateralismo, y sólo cuando Washington actuó de forma unilateral en un contexto en donde ya no existía la "amenaza comunista", en especial durante la era de George W. Bush, su confianza, su influencia y, por ende, su poder, se vieron disminuidos. Bajo este entendimiento, si Estados Unidos desea mantener su posición hegemónica, deberá retomar una práctica de índole multilateral e incluyente que le permita obtener de nueva cuenta la aquiescencia de la sociedad internacional.

\section{Referencias bibliográficas}

Alija Garabito, Adela M. (2001), "El Congreso de Viena y el 'Concierto Europeo', 1814-1830", en Juan Carlos Pereira, Historia de las relaciones internacionales contemporáneas, vol. 1, Madrid: Alianza Universidad, p. 70.

Bengtson, Hermann (1972), "Griegos y persas: El mundo mediterráneo en la Edad Antigua”, Historia universal, tomo 5, Siglo XxI Editores.

Bush, George W. (2010), Decision Points, Nueva York: Crown Publishers.

Cain, P. J., y Hopkins, A. G. (1987), "Gentlemanly capitalism and British expansion overseas, II: New Imperialism 1850-1945”, Economic History Review, 2nd ser, XL(1), pp. 1-26.

Cox, Robert (1987), Production Power and World Order: Social Forces in the Making of History, Nueva York, Columbia University Press.

Du Boff (2003), “U. S. Hegemony: Continuing Declive, Enduring Danger”, Monthly Review, 55(7).

Fergusson, Niall (2003), "Hegemonía o imperio", Foreign Affairs en español, núm. 4, octubre/diciembre. http://www.foreignaffairs-esp.org/2003100 1 faenespreviewessay030418/niall-ferguson/hegemonia-o-imperio.html Gaddis, John Lewis (2002), Sorpresa, seguridad y la experiencia estadounidense, México: LAg Ediciones, p. 63.

Gilpin, Robert (1987), La economía política de las relaciones internacionales, Buenos Aires: Grupo Editor Latinoamericano, Col. de Estudios Internacionales.

Gramsci, Antonio (1975), Selections from the Prison Notebooks, Nueva York: International Publishers.

Gruppi, Luciano (1978), El concepto de hegemonía en Gramsci. Disponible en: http://www.gramsci.org.ar/12/gruppi_heg_en_gramsci.htm 
Hodgson, Godfrey (2009), The Myth of American Exceptionalism, Yale University Press, p. 21.

Hopkins, A. G. (1988), "British Imperialism: Areview and revisión”, Refresh, núm. 7, otoño, pp. 5-8.

Ikenberry, John (2005), “Creating America's World: The Sources of Postwar Liberal Internationalism", septiembre.

Ikenberry, John, y Kupchan, Charles (1990), "Socialization and Hegemonic Power”, International Organization, 44(3), pp. 283-315.

Joseph, Jonathan (2008), "Hegemony and structure-agency problem in International Relations: A scientific realist contribution", Review of International Studies, núm. 34, pp. 109-128.

Joxe, Alan (2002), Imperio del caos: Las repúblicas frente a la dominación estadounidense en la pos-Guerra Fría, Fondo de Cultura Económica, p. 146.

Kagan, Robert (2008), The Return of History and the End of Dreams, Nueva York: Alfred A. Nnopf.

Kennedy, Paul (2007), Auge y caída de las grandes potencias, México: Editorial Debolsillo.

Keohane, Robert (1984), After Hegemony. Cooperation and discord in the world political economy, Princeton: Princeton University Press.

Legro, Jefrey (2000), “Whence American Internationalism”, International Organization, 54(2), pp. 253-289.

Mearsheimer, John (2001), The Tragedy of Great Powers Politics, Chicago: Maple Vaik Book/University of Chicago.

Meurseth, Per (1964), "Balance-of-Power from the Renaissance to the French Revolution”, Journal of Peace Research, 1(2), pp. 120-136.

Mols, Manfred (2010), “¿Del siglo norteamericano al siglo del Pacífico asiático?”, México y la Cuenca del Pacífico, 13(39), pp. 13-24.

Morgenthau, Hans (1985), Politics Among Nations: The Struggle for Power and Peace, Nueva York: McGraw-Hill, p. 45.

Nau, Henry (2002), At home Abroad: Identity and Power in American Foreign Policy, A Century Foundation Book.

Nye, John Jr. (2003), La paradoja del poder norteamericano, Santiago: Taurus, p. 30.

O’Brien, Patrick K. (2002), The Pax Britannica. American Hegemony and the International Economy Order, 1846-1914 and 1941-2001, documento presentado en la sesión 7 del XIII Congress of the International Economy 
History Association in Buenos Aires, martes 23 de julio, sobre "Historical Perspectives on Structural Changes in the World Economy, 1980-2000", organizado por Herman Van der Wee y Eric Buyst (Leuven University).

Petras, James (2005), La histórica reunión de la OEA. Disponible en: www. Jornada.unam.mx/2005/07/03/030a1mun.php

Polanyi, Karl (1989), La gran transformación, crítica del liberalismo económico, Madrid. www.omegalfa.es Biblioteca Libre.

Rapkin, David P., y Braaten, Dan (2009), "Conceptualising hegemonic legitimacy”, Review of International Studies, 35, pp. 113-149.

Renouvin, Pierre, y Duroselle, Jean Baptiste (2000), Introducción a la historia de las relaciones internacionales, México: Fondo de Cultura Económica.

Reus-Smit, Christian (2004), American Power and World Order, Pondicherry: Polity Press.

Rosecrance, Richard (2002), "War and Peace", World Politics, núm. 55, pp. 137-166.

Ruggie, John G. (1992), "Multilateralism: The anatomy of an institution", International Organization, 3(46), pp. 561-598.

Silver, Beverly J., y Arrighi, Giovanni (2003), “Polanyi’s Double 2003 Movement: The Belle Époques of British U. S. hegemony Compared”, Politics \& Society, 31(2), pp. 325-355.

Soderberg, Nancy (2005), El mito de la superpotencia: Uso y abuso del poder, Buenos Aires: El Ateneo, p. 152.

Wallerstein, Immanuel (1989), El moderno sistema mundo: La segunda era de gran expansión de la economía-mundo capitalista, 1739-1850, Nueva York: Siglo XXI Editores.

Winks W., Robin (2000), Historia de la civilización, vol. II, México: Pearson Prentice Hall, p. 315.

Zorgbibe, Charles (1997), Historia de las relaciones internacionales: De la Europa de Bismarck hasta el final de la Segunda Guerra Mundial, tomo I, Madrid: Alianza Editorial. 